\title{
Irrigation and Crop Load Interactions in Relation to Apple Yield and Fruit Size Distribution
}

\author{
A. Naor \\ Golan Research Institute, P.O. Box 97, Kazrin 12900, Israel
}

I. Klein

Institute of Horticulture, ARO, The Volcani Center, Bet Dagan 50250, Israel

I. Doron and Y. Gal

Extension Service, Ministry of Agriculture, P.O. Box 50, Kazrin 12900, Israel

Z. Ben-David

Research and Development, The Golan Heights, P.O. Box 50, Kazrin 12900, Israel

B. Bravdo

Department of Viticulture, The Faculty of Agriculture, The Hebrew University of Jerusalem, P.O.Box 12, Rehovot 76100, Israel

\begin{abstract}
ADDrTIONAL INDEX wORDs. assimilates availability
Abstract. The interaction between irrigation and crop load with respect to fruit size distribution was investigated in a 'Golden Delicious' apple (Malus domestica Borkh) orchard located in a semi-arid zone. Irrigation levels during the main fruit expansion phase ranged from 0.42 to 1.06 of the Class A pan evaporation coefficient. Crop load was adjusted to 100 to 450 fruit/tree in the 1250 trees/ha orchard by hand thinning. Total yield was not affected by irrigation level up to a crop load of 200 fruit/tree. Yield of all grades $>65 \mathrm{~mm}$ was affected by irrigation level for higher crop densities. The yield of fruit of diameter $<75 \mathrm{~mm}$ was not affected by increasing the Class A pan evaporation coefficient above 0.75 . Our data indicate that availability of assimilates may limit the size of fruit with potential to grow larger than $70 \mathrm{~mm}$ in diameter at all crop loads higher than 200 fruit/tree. This limitation increases with decreasing irrigation level. The volumetric relative growth rate (VRGR) increased with irrigation level and with decreasing crop load. VRGR was more affected by crop load than by irrigation level in the ranges studied.
\end{abstract}

Fruit size is a major factor of 'Golden Delicious' apple quality. Since fruit size is affected by crop load and water deficit, it is of economic interest to optimize crop load and water deficit to maximize the number of large fruit.

Crop load affects fruit size of apples (Assaf et al., 1982; Erf and Proctor, 1987; Forshey and Elfving, 1989); however, the mechanisms involved are not fully understood. Compared with nonfruiting trees, fruiting apple trees have greater stomatal aperture (Hansen, 1971) and stomatal conductance (Erf and Proctor, 1987; Monselise and Lenz, 1980a), higher assimilation rate (Monselise and Lenz, 1980b; Schechter et al., 1994; Wiebbe et al., 1993), lower leaf water potential (Erf and Proctor, 1987), and higher water consumption (Hansen, 1971; Lenz, 1986). Defruited trees had larger shoot growth and lower dry mass production than fruiting trees (Forshey and Elfving, 1989; Hansen, 1971; Lenz, 1986; Schechter et al., 1994). Irrigation level affected soil water availability and, thereby, plant water status, yield, and fruit size (Assaf et al., 1982; Erf and Proctor, 1987; Irving and Drost, 1987). In most reports, extreme cases of fruiting and defruited trees were studied (Hansen, 1971; Lenz 1986), whereas only a few dealt with varied fruit levels (Assaf et al., 1982; Erf and Proctor, 1987). Since irrigation scheduling interacted with crop load on fruit size (Assaf et al., 1982) it is important to study the combined effect of these two factors.

The objective of the present project was to study the combined effect of irrigation and crop load on yield and fruit size distribution.

Received for publication 7 Aug. 1996. Accepted for publication 27 Nov. 1996. The cost of publishing this paper was defrayed in part by the payment of page charges. Under postal regulations, this paper therefore must be hereby marked advertisement solcly to indicatc this fact.

\section{Materials and Methods}

The experimental site was in the Golan Heights, Israel $\left(33^{\circ} \mathrm{N}\right.$, $36^{\circ} \mathrm{E}$ ), $900 \mathrm{~m}$ above mean sea level, which is a semi-arid zone with no summer rains. The average precipitation (October-April) in this area is about $1000 \mathrm{~mm}$.

The experimental plot consisted of a 12-year-old drip-irrigated commercial orchard of 'Golden Delicious' apple on 'MallingMerton 106' (M.M. 106) rootstock spaced $2 \times 4 \mathrm{~m}$ apart. The irrigation system consisted of two lateral lines per row spaced 1.0 $\mathrm{m}$ apart, with $2.3 \mathrm{~L} \cdot \mathrm{h}^{-1}$ pressure-compensated inline drippers, spaced $0.8 \mathrm{~m}$ apart. The experimental plot was irrigated until midJune according to commercial practice: irrigation started in May at a Class A pan evaporation coefficient of 0.30 and gradually increased up to 0.45 in mid-June (differential treatments started at mid-June). An additional $90 \mathrm{~mm}$ of water was applied to all treatments after harvest. The experimental design enabled the study of the interaction of irrigation and crop load during the main period of fruit growth.

The experiment was a split-plot factorial design with five irrigation levels as main plots and crop load as subplots. The treatments were replicated five times in a complete randomized block design. Each main plot (irrigation treatment) consisted of four adjacent rows with four trees each, and only the four inner trees were used for the four crop load treatments. Five irrigation levels with Class A pan evaporation coefficients of $0.42,0.58$, $0.75,0.90$, and 1.06 were implemented. The fruit on each tree were counted at the beginning of June and thinned to four fruit levels: 0 to 150,151 to 250,251 to 350 , and $>350$.

Twenty fruit per tree were tagged after fruit thinning, and their diameters were measured every 2 weeks with a fruit diameter 
Table 1. Cumulative and daily irrigation rates and average pan evaporation coefficients in the five irrigation treatments.

\begin{tabular}{lcc}
\hline \hline Avg. pan evaporation coefficient & Cumulative irrigation up to harvest (mm) & Avg. daily irrigation rate (mm) \\
\hline 0.42 & 387 & 2.8 \\
0.58 & 482 & 3.9 \\
0.75 & 585 & 5.0 \\
0.90 & 679 & 6.1 \\
1.06 & 775 & 7.1 \\
\hline
\end{tabular}

gauge (Cranston Machinery Co. Inc. Ore.). Fruit volume was calculated using a polynomial equation, which calibrated fruit volume to fruit diameter. Volumetric relative growth rate (VRGR) was calculated according to Atkinson et al. (1995).

The fruit from the experimental plots were harvested on 10 Sept. The fruit of each tree were weighed, and size distribution was determined by means of a commercial grading machine ( 55 to 75 $\mathrm{mm}$ in diameter.

Analysis of variance followed by Duncan's multiple range test using the SAS GLM (SAS Institute, Cary, N.C.) procedure, and multiple regression analysis using the SAS REG procedure was conducted on VRGR as a dependent variable and irrigation level and crop load as independent variables.

\section{Results and Discussion}

Cumulative irrigation water applied up to harvest ranged from 387 to $775 \mathrm{~mm}$ (Table 1). An additional $90 \mathrm{~mm}$ was applied to all treatments after harvest. The average midsummer Class A pan evaporation rate was $7 \mathrm{~mm} \cdot \mathrm{d}^{-1}$.

Crop yields increased with irrigation level (Table 2) and crop load, whereas no interaction between irrigation and crop load was generally apparent. Crop load at the highest irrigation treatment was greater than other treatments (Table 2).

The relative yield (percent of total) within each size grade increased with irrigation level up to a coefficient of 0.75 (Table 2), while differences in relative yield, between irrigation levels, increased considerably with fruit size. Relative yield tended to decrease with increasing crop load and fruit size category (Table 2). The most significant effect was found in the $>75-\mathrm{mm}$ category.
Irrigation levels interacted positively with fruit levels in the $>65$ $\mathrm{mm}$ fruit size category (Table 2), although the differences were relatively small.

The crop yield increased as expected with crop load (Fig. 1A). The total yield for crop loads up to 200 fruit/tree did not respond to irrigation, whereas an increase with irrigation level was apparent for higher crop loads (Fig. 1A). The effect of irrigation level on crop yield increased with fruit size (Fig. 1 B-D). The yield of fruit of a diameter $>75 \mathrm{~mm}$ increased with crop load up to about 200 fruit/tree in all irrigation treatments (Fig. 1D). A further increase in crop load was accompanied by a reduction in yield of the $>75$ $\mathrm{mm}$ category in the two lowest irrigation coefficient treatments ( 0.42 and 0.58 of Class A pan evaporation). The crop yield of the $>75 \mathrm{~mm}$ size category leveled off with increasing crop load, with irrigation coefficients $>0.58$ (Fig. 1D).

Irrigation coefficients higher than $0.75 \mathrm{did}$ not result in increased yield of fruit $>65-\mathrm{mm}$ (Fig. 1, Table 2). This may indicate that irrigation should not exceed 0.75 of Class A pan evaporation rate for producing fruit $>65 \mathrm{~mm}$ in diameter.

VRGR increased toward day of year 200 and then decreased in all irrigation treatments (Fig. 2A) and at all crop loads (Fig. 2B). This growth pattern for apples conforms with sigmoidal growth (Atkinson et al., 1995; Pratt, 1988) rather than expolinear (Lakso et al., 1995) or linear (Assaf et al., 1975, 1982) patterns. VRGR increased with increasing irrigation level (Fig. 2A) and with decreasing crop load (Fig. 2B), although VRGR was more sensitive to crop load than to irrigation level in the ranges studied (Table 2). To confirm this, a multiple regression analysis was conducted between VRGR as a dependent variable and crop load and irrigation level as independent variables. The coefficients of determina-

Table 2. Effects of irrigation and crop load on yield ( $\mathrm{t} \cdot \mathrm{ha}^{-1}$ ) and relative yield (percentage of total) of selected size grades of 'Golden Delicious' apple on 'M.M. 106' rootstock (irrigation levels are pan evaporation coefficients; crop loads are average number of fruit/tree).

\begin{tabular}{|c|c|c|c|c|c|c|c|c|}
\hline & \multirow{2}{*}{$\begin{array}{l}\text { Total } \\
\text { yield } \\
\left(\mathrm{t} \cdot \mathrm{ha}^{-1}\right)\end{array}$} & \multicolumn{3}{|c|}{$\begin{array}{l}\text { Yield }\left(\mathrm{t} \cdot \mathrm{ha}^{-1}\right) \\
\text { exceeding fruit size }\end{array}$} & \multicolumn{3}{|c|}{$\begin{array}{l}\text { Percent of yield } \\
\text { exceeding fruit size }\end{array}$} & \multirow{2}{*}{$\begin{array}{c}\text { Fruit/ } \\
\text { tree }\end{array}$} \\
\hline & & $65 \mathrm{~mm}$ & $70 \mathrm{~mm}$ & $75 \mathrm{~mm}$ & $65 \mathrm{~mm}$ & $70 \mathrm{~mm}$ & $75 \mathrm{~mm}$ & \\
\hline \multicolumn{9}{|c|}{ Irrigation level (I) } \\
\hline 0.42 & $52 c^{2}$ & $48 \mathrm{~d}$ & $39 c$ & $14 b$ & $94 \mathrm{~b}$ & $78 \mathrm{c}$ & $33 \mathrm{~b}$ & $257 \mathrm{~b}$ \\
\hline 0.58 & $54 \mathrm{bc}$ & $52 \mathrm{~cd}$ & $45 \mathrm{c}$ & $17 \mathrm{~b}$ & $95 \mathrm{~b}$ & $86 b$ & $38 \mathrm{~b}$ & $258 \mathrm{~b}$ \\
\hline 0.75 & $59 \mathrm{~b}$ & $58 \mathrm{bc}$ & $54 \mathrm{~b}$ & $29 a$ & $98 \mathrm{a}$ & $93 \mathrm{a}$ & $59 \mathrm{a}$ & $267 b$ \\
\hline 0.90 & $60 \mathrm{~b}$ & $59 \mathrm{~b}$ & $56 \mathrm{ab}$ & $32 \mathrm{a}$ & $98 \mathrm{a}$ & 93 a & $56 a$ & $269 \mathrm{~b}$ \\
\hline 1.06 & $68 \mathrm{a}$ & $66 a$ & $63 \mathrm{a}$ & $38 \mathrm{a}$ & $98 a$ & 93 a & $61 \mathrm{a}$ & $300 \mathrm{a}$ \\
\hline \multicolumn{9}{|c|}{ Crop load (C) } \\
\hline $0-150$ & $26 \mathrm{~d}$ & $25 \mathrm{~d}$ & $24 \mathrm{~d}$ & $19 \mathrm{~b}$ & $97 \mathrm{a}$ & $93 a$ & $72 \mathrm{a}$ & \\
\hline $151-250$ & $49 c$ & $48 \mathrm{c}$ & $47 \mathrm{c}$ & $30 \mathrm{a}$ & $98 a$ & $94 \mathrm{a}$ & $59 \mathrm{~b}$ & \\
\hline $251-350$ & $65 \mathrm{~b}$ & $64 b$ & $59 \mathrm{~b}$ & $30 \mathrm{a}$ & $98 \mathrm{a}$ & $90 \mathbf{a}$ & $45 c$ & \\
\hline$>350$ & $88 \mathrm{a}$ & $83 \mathrm{a}$ & $71 \mathrm{a}$ & $26 a b$ & $94 \mathrm{a}$ & $80 \mathrm{~b}$ & $28 \mathrm{~d}$ & \\
\hline $\mathrm{I} \times \mathrm{C}$ & NS & NS & NS & NS & $0.04^{y}$ & NS & NS & \\
\hline
\end{tabular}

${ }^{\mathrm{z}}$ Results within a column followed by different letters differ significantly by Duncan's multiple range test, $p=0.05$.

${ }^{\mathrm{y}}$ Significance level. 


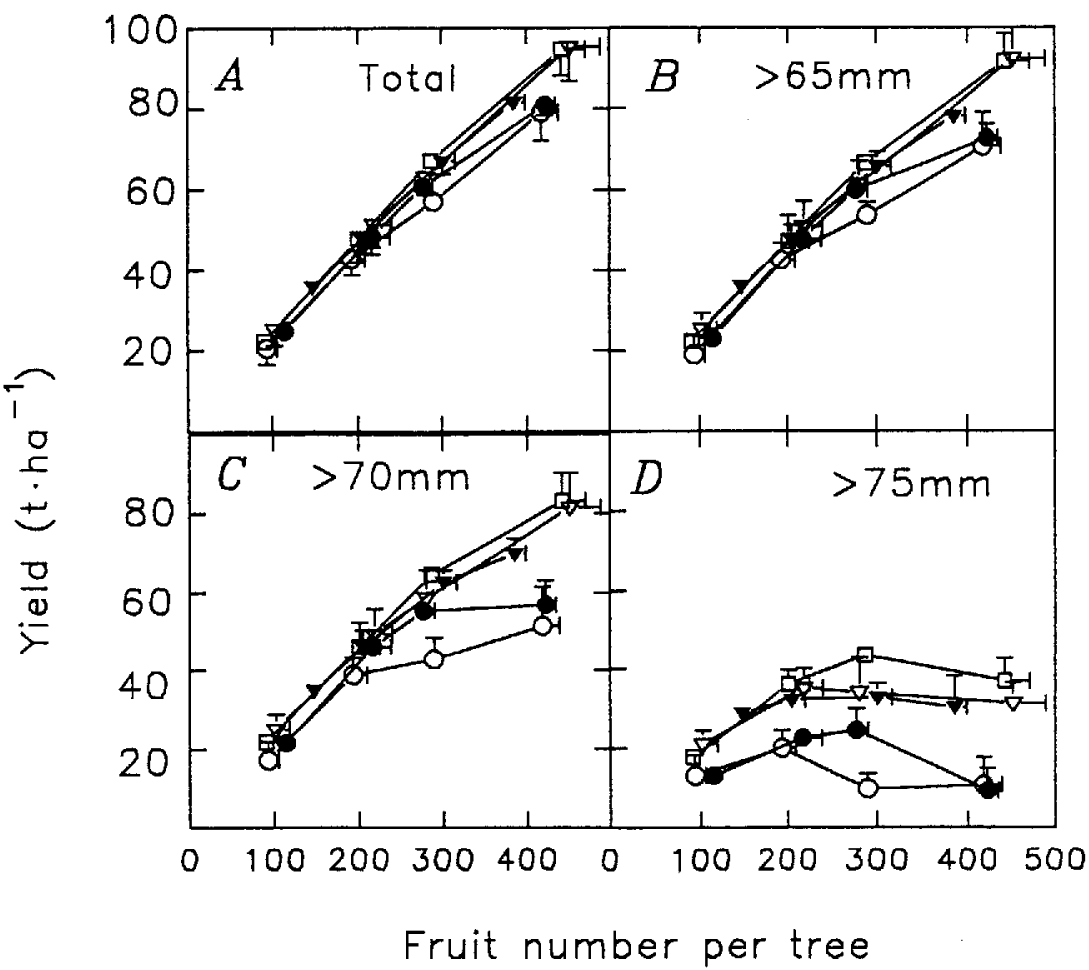

Fig. 1. Crop yield ( $\mathrm{t}$ ha $\mathrm{a}^{-1}$ ) of four fruit size categories as a function of fruit number per tree. (A) Total yield; (B) Fruit $>65 \mathrm{~mm}$; (C) Fruit $>70 \mathrm{~mm}$; (D) Fruit $>75 \mathrm{~mm}$. Symbols denote different Class A pan evaporation coefficients $(\mathrm{O}=0.42, \Theta=0.58, \nabla=0.75, \boldsymbol{\nabla}$ $=0.90, \square=1.06$ ). Bars denote standard error.

next-smaller size grade. The percentage of fruit that did not reach their potential size in each grade was calculated as follows: fruit in the current size grade that did not reach their pofential size $=$ actual frequency in the current size grade - potential frequency in the current size grade (lowest crop load) frequency of fruit that were shifted from the next larger grade to the current size grade.

Fruit from the medium crop load that did not reach their potential size (Fig. $3 \mathrm{C}$ and $\mathrm{D}$ ) were concentrated in the largest grade $(>75 \mathrm{~mm})$, while those of the highest crop load that did not reach their potential size (Fig, $3 \mathrm{C}$ and D) were concentrated in the two largest grades $(>70 \mathrm{~mm})$. It would appear that the whole-tree assimilate availability decreased with crop load, but fruit of larger potential size were more affected than those of smaller potential size. This suggests that a limitation of assimilate availability was apparent on a fruit basis, as manifested in the decrease in VRGR with increasing crop load (Fig. 2B). tion $\left(r^{2}\right)$ were highest on day of year 200 (Table 3), and VRGR generally had a higher partial correlation with crop load than with irrigation level (Table 3), suggesting that VRGR is more sensitive to crop load than to irrigation coefficient in the ranges studied. The high correlation between VRGR and crop load and irrigation levels at day of year 200 suggests that fruit volume is less affected by irrigation at the beginning of the fruit expansion phase and close to harvest than it is during the main expansion phase. There is a possibility, however, that the lower correlation at the beginning of the fruit expansion phase (Table 3 ) is due to higher measurement error because of the smaller fruit.

Total yield at the highest irrigation level increased linearly with fruit level up to about 300 fruit/tree, where a deviation from linearity was apparent for higher fruit levels (Fig. 1A); the highest yield efficiency on a trunk cross-sectional basis was $0.64 \mathrm{~kg} \cdot \mathrm{cm}^{-2}$. A linear relationship between yield efficiency and fruit number was reported for yield efficiencies up to $1.25 \mathrm{~kg} \cdot \mathrm{cm}^{-2}$ in 'McIntosh' apples grafted on 'M.M. 106' rootstock (Forshey and Elfving, 1977). The difference in variety and climatic conditions may well explain these differences.

The proportional response of yield to crop load up to $200 \mathrm{fruit} /$ tree indicates no limitation in availability of assimilates or other growth factors. The deviation from linear relationship of crop yield to crop load increased with fruit diameter under study and decreased with water application (Fig. 1) probably because of some assimilate or other growth factor limitations. To explore this topic further, fruit size distributions at the lowest and highest irrigation levels were compared at three crop loads (Fig. 3). The frequency of fruit $>75 \mathrm{~mm}$ decreased with increasing crop load at the lowest (Fig. 3A) and the highest (Fig. 3B) irrigation levels, while the opposite was observed for fruit diameters of 65 to 70 and 70 to 75 $\mathrm{mm}$. The frequency of fruit in the $<65$-mm grade was not affected by crop load. To explain the effect of crop load on fruit size distribution, two assumption were made: first, the lowest crop level $(<200$ fruit/tree) is small enough to represent a first approximation to the potential fruit size distribution; and second, fruit that did not reach their potential size in each grade were found in the

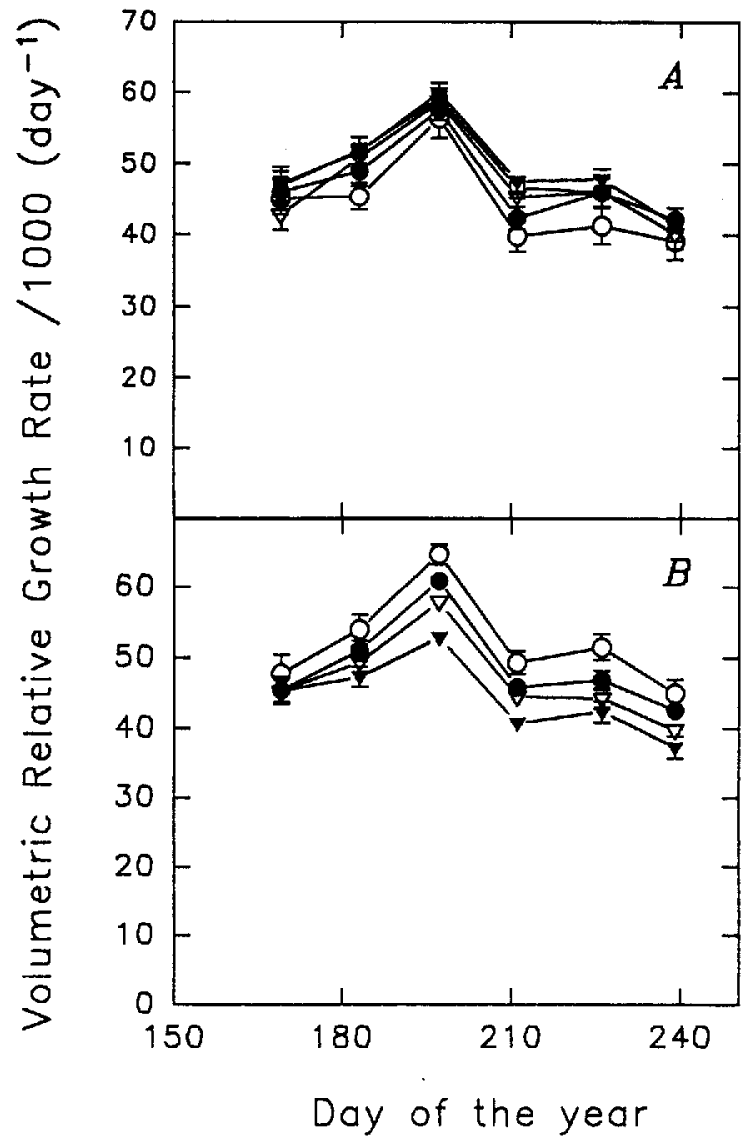

Fig. 2. Seasonal volumetric relative growth rate(VRGR). (A) Irrigation leveleffectaccording tovarious Class A pan evaporation coefficients $(\mathrm{O}=0.42, \boldsymbol{Q}=0.58, \nabla=0.75, \boldsymbol{\nabla}=0.90, \square=1.06)$. (B) Crop loads as fruit number/tree $(O=0$ to $150, \Theta=151$ to $250, \nabla=251$ to 350 , $\boldsymbol{\nabla}=>350$ ). Bars denote standard error. 
Table 3. The coefficient of determination $\left(r^{2}\right)$ for partial correlation coefficients between volumetric relative growth rate and irrigation level and crop load during the growing season for 'Golden Delicious' apple on 'M.M. 106' rootstock.

\begin{tabular}{lcc}
\hline \hline Day of year & Irrigation level & Crop load \\
\hline 183 & 0.106 & 0.092 \\
197 & 0.054 & 0.391 \\
211 & 0.21 & 0.21 \\
226 & 0.06 & 0.16 \\
239 & 0.0 & 0.19 \\
\hline
\end{tabular}

\section{Summary and Conclusions}

Crop yield of fruit of 65 to $75 \mathrm{~mm}$ was not affected by irrigation level at crop loads lower than 200 fruit/tree. All yield grades $>65$ $\mathrm{mm}$ in all irrigation levels were reduced at crop loads higher than $200 \mathrm{fruit} / \mathrm{tree}$. The yield of fruit in diameter grades $<75 \mathrm{~mm}$ was not affected by increasing the irrigation level to Class A pan evapora-

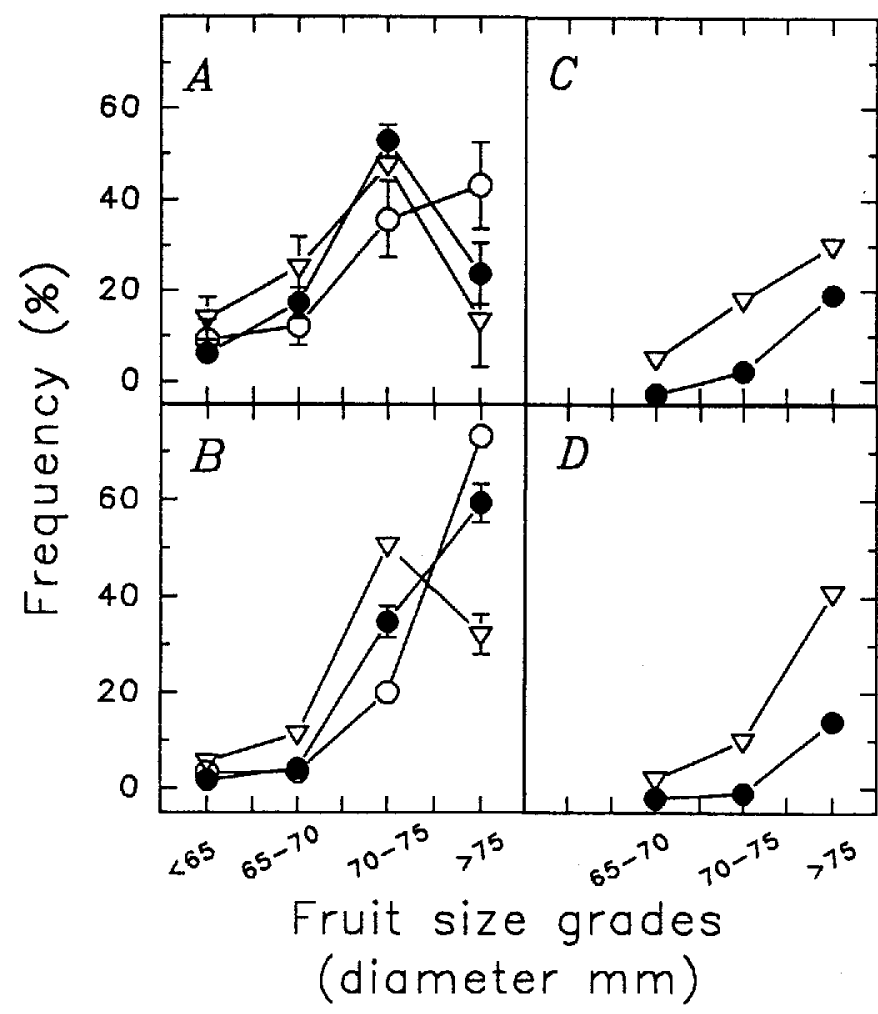

Fig. 3. Fruit size distribution for three crop loads as fruit number $/$ tree $(O=0$ to 200

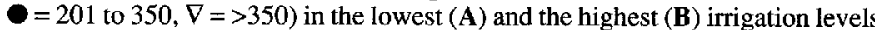
( 0.42 and 1.06 of Class A pan evaporation rate, respectively). Fruit that did not reach their potential size (actual - potential frequency - frequency of fruit that were shifted from the nearest greater size grade) in the lowest (C) and highest (D) irrigation levels. tion coefficients above 0.75 , whereas the yield of fruit $>75 \mathrm{~mm}$ increased. This suggests that higher irrigation levels might increase the yield of fruit larger than $75 \mathrm{~mm}$. Furthermore, irrigation should not increase above 0.75 of the Class A pan evaporation coefficient for the production of apples 65 to $75 \mathrm{~mm}$ in diameter.

Our data suggest that availability of assimilates or other growth factors limits the size of fruit of potential size $>75 \mathrm{~mm}$ in all crop loads and fruit $>70 \mathrm{~mm}$ in the medium and higher crop loads. This limitation increases with decreasing irrigation level. The VRGR of all treatments peaked in mid-July, showing a slightly sigmoidal growth pattern. VRGR increased with increasing irrigation level and decreasing crop load and was more sensitive to crop load than to irrigation level in the ranges studied.

\section{Literature Cited}

Assaf, R., I. Levin, and B. Bravdo. 1975. Effect of irrigation regime on trunk and fruit growth rates, quality and yield of apple tree. J. Hort. Sci. 50:481-493.

Assaf, R., I. Levin, and B. Bravdo. 1982. Apple fruit growth as a measure of irrigation control. HortScience 17:59-61.

Atkinson, C.J., L. Taylor, and J.M. Taylor. 1995. The influence of temperature and water supply on apple fruit growth and the development of orchard-grown trees. J. Hort. Sci. 70:691-703.

Erf, J.A. and J.T.A. Proctor. 1987. Changes in apple leaf water status and vegetative growth as influenced by crop load. J. Amer. Soc. Hort. Sci. 112:617-620.

Forshey, C.G. and D.C. Elfving. 1977. Fruit number, fruit size, and yield relationships in 'McIntosh' apples. J. Amer. Soc. Hort. Sci. 102:399_ 402.

Forshey, C.G. and D.C. Elfving. 1989. The relationship between vegetative growth and fruiting in apple trees. Hort. Rev. 11:229-287.

Hansen, P. 1971. The effect of fruiting upon transpiration rate and stomatal opening in apple leaves. Physiol. Plant. 25:181-183.

Irving, D.E. and J.H. Drost. 1987. Effects of water deficit on vegetative growth, fruit growth and fruit quality of Cox's Orange Pippin apple. J. Hort. Sci. 62:427-432.

Lakso, A.N., L. Corelli Grapapadelli, J. Barnard, and M.C. Goffinet. 1995. An expolinear model of the growth pattern of apple fruit. J. Hort. Sci. 70:389-394.

Lenz, F. 1986. Fruit effects on transpiration and dry matter production in apples, p. 101-104. In: A.N. Lakso and F. Lenz (eds.). Regulation of photosynthesis in fruit trees. 1986. Symp. Proc. Publ., N.Y. State Agr. Expt. Sta., Geneva.

Monselise, S.P. and F. Lenz. 1980a. Effect of fruit load on stomatal resistance, specific leaf weight, and water content of apple trees. Gartenbauwissenschaft 45:188-191.

Monselise, S.P. and F. Lenz. 1980b. Effect of fruit load on photosynthetic rates of budded apple trees. Gartenbauwissenschaft 45:220-224.

Pratt, C.S. 1988. Apple flower and fruit: morphology and anatomy. Hort. Rev. 10:273-308.

Schechter, I., J.T.A. Proctor, and D.C. Elfving. 1994. Carbon exchange rate and accumulation in limbs of fruiting and nonfruiting apple trees. $J$. Amer. Soc. Hort. Sci. 119:150-156.

Wiebbe, M.L., M.M. Blanke, and F. Lenz. 1993. Effect of fruiting on carbon budgets of apple tree canopies. Trees 8:56-60. 